NASA/TM-2004-212941

\title{
Development of a Dynamic, End-to-End Free Piston Stirling Convertor Model
}

Timothy F. Regan

Sest, Inc., Middleburg Heights, Ohio

Scott S. Gerber

ZIN Technologies, Inc., Cleveland, Ohio

Mary Ellen Roth

Glenn Research Center, Cleveland, Ohio 
Since its founding, NASA has been dedicated to the advancement of aeronautics and space science. The NASA Scientific and Technical Information (STI) Program Office plays a key part in helping NASA maintain this important role.

The NASA STI Program Office is operated by Langley Research Center, the Lead Center for NASA's scientific and technical information. The NASA STI Program Office provides access to the NASA STI Database, the largest collection of aeronautical and space science STI in the world. The Program Office is also NASA's institutional mechanism for disseminating the results of its research and development activities. These results are published by NASA in the NASA STI Report Series, which includes the following report types:

- $\quad$ TECHNICAL PUBLICATION. Reports of completed research or a major significant phase of research that present the results of NASA programs and include extensive data or theoretical analysis. Includes compilations of significant scientific and technical data and information deemed to be of continuing reference value. NASA's counterpart of peerreviewed formal professional papers but has less stringent limitations on manuscript length and extent of graphic presentations.

- TECHNICAL MEMORANDUM. Scientific and technical findings that are preliminary or of specialized interest, e.g., quick release reports, working papers, and bibliographies that contain minimal annotation. Does not contain extensive analysis.

- CONTRACTOR REPORT. Scientific and technical findings by NASA-sponsored contractors and grantees.
- CONFERENCE PUBLICATION. Collected papers from scientific and technical conferences, symposia, seminars, or other meetings sponsored or cosponsored by NASA.

- SPECIAL PUBLICATION. Scientific, technical, or historical information from NASA programs, projects, and missions, often concerned with subjects having substantial public interest.

- TECHNICAL TRANSLATION. Englishlanguage translations of foreign scientific and technical material pertinent to NASA's mission.

Specialized services that complement the STI Program Office's diverse offerings include creating custom thesauri, building customized databases, organizing and publishing research results ... even providing videos.

For more information about the NASA STI Program Office, see the following:

- Access the NASA STI Program Home Page at http://www.sti.nasa.gov

- E-mail your question via the Internet to help@sti.nasa.gov

- Fax your question to the NASA Access Help Desk at 301-621-0134

- Telephone the NASA Access Help Desk at 301-621-0390

- Write to:

NASA Access Help Desk

NASA Center for AeroSpace Information 7121 Standard Drive

Hanover, MD 21076 
NASA/TM-2004-212941

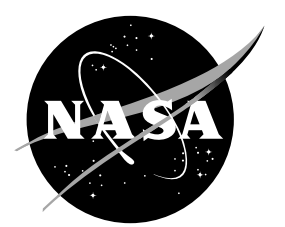

\section{Development of a Dynamic, End-to-End Free Piston Stirling Convertor Model}

Timothy F. Regan

Sest, Inc., Middleburg Heights, Ohio

Scott S. Gerber

ZIN Technologies, Inc., Cleveland, Ohio

Mary Ellen Roth

Glenn Research Center, Cleveland, Ohio

Prepared for the

Space Technology and Applications International Forum (STAIF-2003) cosponsored by the United States Department of Energy and the National Aeronautics and Space Administration Albuquerque, New Mexico, February 2-5, 2003

National Aeronautics and Space Administration

Glenn Research Center 


\section{Acknowledgments}

The authors wish to thank Ansoft Corporation for the use of its Simplorer software suite for this project. The authors hold an evaluation license for the software at the present time and graphics from the suite could not have been used without the permission of Ansoft. The work described in this paper was performed for the Office of Space Science (Code S) and the Office of Aerospace Technology (Code R) at NASA Headquarters, both of which provided funding for these efforts.

This report contains preliminary

findings, subject to revision as analysis proceeds.

Trade names or manufacturers' names are used in this report for identification only. This usage does not constitute an official endorsement, either expressed or implied, by the National Aeronautics and Space Administration.

Available from

NASA Center for Aerospace Information 7121 Standard Drive

Hanover, MD 21076
National Technical Information Service 5285 Port Royal Road Springfield, VA 22100 


\title{
Development of a Dynamic, End-to-End Free Piston Stirling Convertor Model
}

\author{
Timothy F. Regan \\ Sest, Inc. \\ Middleburg Heights, Ohio 44130 \\ Scott S. Gerber \\ ZIN Technologies, Inc. \\ Cleveland, Ohio 44135 \\ Mary Ellen Roth \\ National Aeronautics and Space Administration \\ Glenn Research Center \\ Cleveland, Ohio 44135
}

\begin{abstract}
A dynamic model for a free-piston Stirling convertor is being developed at the NASA Glenn Research Center. The model is an end-to-end system model that includes the cycle thermodynamics, the dynamics, and electrical aspects of the system. The subsystems of interest are the heat source, the springs, the moving masses, the linear alternator, the controller, and the end-user load. The envisioned use of the model will be in evaluating how changes in a subsystem could affect the operation of the convertor. The model under development will speed the evaluation of improvements to a subsystem and aid in determining areas in which most significant improvements may be found. One of the first uses of the end-to-end model will be in the development of controller architectures. Another related area is in evaluating changes to details in the linear alternator.
\end{abstract}

\section{INTRODUCTION}

A Stirling Radioisotope Generator (SRG) is being considered for use on NASA deep space missions as well as unmanned Mars rovers. A free-piston Stirling convertor is the power conversion technology used in the SRG. One of NASA Glenn Research Center's (GRC) goals for the Stirling convertor is to increase its specific power (watts per $\mathrm{kg}$ ) in order to enhance the SRG's efficacy on such missions. Two areas have been identified as prime targets for mass reduction, the linear alternator and the tuning capacitor in the controller. An improvement such as mass reduction in an individual subsystem does not necessarily translate into a system-wide improvement. An end-to-end dynamic system model would be beneficial to evaluate proposed changes, especially the effect of proposed changes on overall system performance. GRC has been active in Stirling research for many years and has both hardware and analytical capability at its disposal that can be used in development and verification of such a model. The model developed at GRC need not be stand-alone and all-inclusive. Much of the heat transfer data can be derived from industry standard Stirling design codes like Sage and used as input to the end-to-end model in the form of lumped parameters. Results will be verified using the Stirling convertor hardware available at GRC. Multi-simulation software packages are now available that make it possible to marry power electronics simulations with mechanical and thermal simulations and state diagrams. Some software suites offer hooks into the finite element electromechanical analysis software used at GRC for analysis of the linear alternator in the Stirling convertor. This paper will describe, in detail the model developed, simulation results to date, and planned future activities.

\section{PLANT MODEL}

Models of the Stirling convertor have been developed over the years. (Berchowitz, Urieli and Rallis, 1977, Benvenuto and de Monte, 1990, Ulusoy and McCaughan, 1993) The effort described in this paper is not the development of new model theory so much as to apply that theory using the multi simulation software environments that have recently become available. When the Stirling convertor model is implemented in such a software environment, the thermal aspects of the cycle and the electronic control aspects become more tractable.

The free-piston Stirling convertor is a reciprocating mechanical oscillator driven by heat energy. The convertor consists of a pressurized vessel in which are located a displacer, a piston, and a linear alternator. The vessel is filled 
with a working fluid such as Helium. The key components are illustrated in Figure 1. This illustration depicts a generic Stirling convertor having annular heat exchangers and regenerator. There have been many variations in free-piston Stirling convertors designs; however the layout shown in Figure 1 will be used for this paper. Figure 1 also shows the volumes and components labeled with their respective parameters used in the analysis.

\section{Mechanical Model}

The mechanical model is described in terms of gas dynamics and the mass-spring-damper systems comprising its moving parts. The machine is driven by the interaction of changing pressures and changing volumes. Neglecting inertia and flow loss pressure drops, the relation between pressure and working space volumes is given by

$$
P=M_{w} \cdot R_{G a s} \div\left(\frac{V_{h}}{T_{h}}+\frac{V_{r}}{T_{r}}+\frac{V_{k}}{T_{k}}+\frac{V_{e}}{T_{e}}+\frac{V_{c}}{T_{c}}\right)
$$

$\mathrm{M}_{\mathrm{w}}$ is the mass of the gas in the working space during operation. Equation 1 assumes that the pressures in each of the spaces mentioned on the RHS are the same at every instant in time. The gas in the displacer and the bounce space do not appear in Equation (1) because these volumes communicate with the working space only through slow leaking clearance seals. One can see that the pressure $\mathrm{P}$ will vary above and below a mean pressure as the volumes $\mathrm{V}_{\mathrm{c}}$ and $\mathrm{V}_{\mathrm{e}}$ vary with piston and displacer motion. The present model assumes that these the bounce space and displacer interior are always at the mean pressure of the working space. The mean pressure is calculated

$$
P_{m}=M_{w} \cdot R_{G a s} \div\left(\frac{V_{h}}{T_{h}}+\frac{V_{r}}{T_{r}}+\frac{V_{k}}{T_{k}}+\frac{V_{e 0}}{T_{e}}+\frac{V_{c 0}}{T_{c}}\right)
$$

where the $\mathrm{V}_{\text {eо }}$ and $\mathrm{V}_{\mathrm{co}}$ are the equilibrium volumes of the expansion and compression spaces.

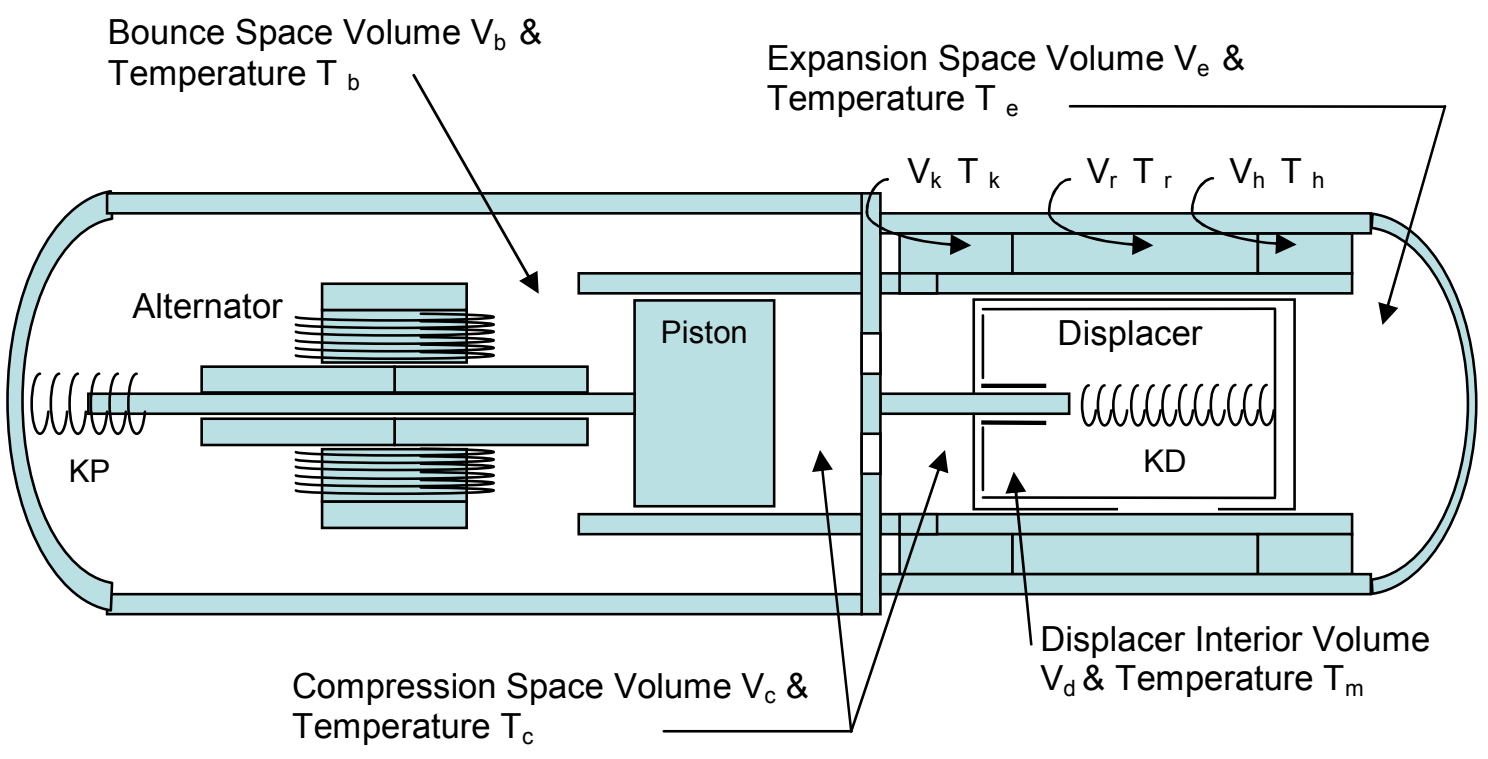

FIGURE 1. Convertor Arrangement \& Model Nomenclature. Displacements and forces are positive to the right. Vk, Vr and $\mathrm{Vh}$ represent the volumes of the annular heat exchangers. Subscripts $\mathrm{k}, \mathrm{r}$ and $\mathrm{t}$ are for cold, regenerator and hot. 


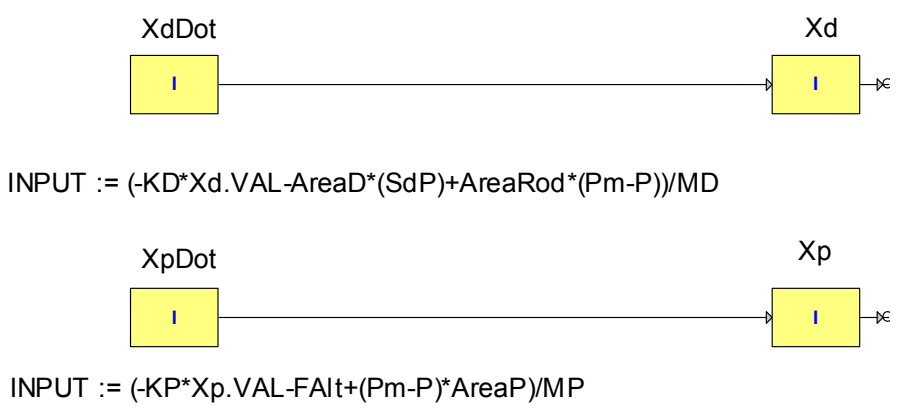

FIGURE 2. Sum-of-Forces Block Diagram. XdDot, Xd, XpDot and Xp are Integrators. Time-varying quantities appearing in the input expression for integrators XdDot and XpDot such as P, Pm, FAlt and SdP (sum of heat exchanger pressure drops) are recalculated each integration step.

If temperatures are considered to remain constant throughout a cycle, then the pressure $\mathrm{P}$ will be the highest when the sum $V_{e} / T_{e}+V_{c} / T_{c}$ is at minimum. The pressure $P$ will be the lowest when the sum is at maximum. Gas pressure creates forces on the areas bounding them. Pressure forces combined with spring forces and damping forces in a free-body diagram appear as the numerators of the input expressions in the block diagrams shown in Figure 2. The four rectangular blocks in the figure are integrators. Two second-order systems are shown in the figure.

Springs with constants KP and KD, along with piston mass and displacer mass, MP and MD, respectively, provide energy storage required to make each system a spring-mass mechanical oscillator. KP may be mechanical if flexures are used, or may be a result of the gas-spring pressures forces. The linear alternator also may contain some spring content but it is more convenient to represent it as part of the linear alternator system model. Spring rates are selected to make both the displacer and the piston systems resonate near the intended operating frequency of the convertor.

Damping in the displacer system is generally provided by the pressure drop in the heat exchangers. The pressure drop is a result of the flow of the working fluid through the heater, the regenerator, and the cooler. The damping in the piston system is provided by the force noted FAlt in Figure 2. FAlt is an electromechanical force due to instantaneous load current in the linear alternator windings, and is directly proportional to the instantaneous current flowing in the alternator stator. Current flows in response to the electromotive force (EMF). The alternator EMF is the time rate of change of the flux linked by the linear alternator. That flux varies directly with piston position. The time rate of change of flux linkages (the alternator EMF) is proportional to the time rate of change of piston position (piston velocity). Any force proportional to the alternator EMF is proportional to piston velocity and therefore appears as a damping force. Instantaneous load current is proportional to alternator EMF in any electric circuit having unity power factor.

For the cycle to operate, heat is applied to the expansion space and waste heat removed from the compression space. The pressure in the displacer interior remains constant and is not a part of the cycle. As the displacer moves, a net force due to $\left(\mathrm{P}_{\mathrm{m}}-\mathrm{P}\right) * \mathrm{~A}_{\mathrm{r}}$ will act upon the displacer. When $\mathrm{P}$ is greater than $\mathrm{P}_{\mathrm{m}}$, the force will be negative. The displacer will move in the negative $X_{d}$ direction, (to the left in Figure 1). As the displacer moves to the left, the volume $\mathrm{V}_{\mathrm{e}}$ grows, the pressure $\mathrm{P}$ increases per equation (1). The power piston will move in the negative direction, expanding the working fluid and thus lowering the pressure. At some point, the pressure $\mathrm{P}$ becomes less than $\mathrm{P}_{\mathrm{m}}$. At that point, the term $\left(\mathrm{P}_{\mathrm{m}}-\mathrm{P}\right)$ becomes positive and the force on the displacer is directed to the right. As the displacer moves to the right, $\mathrm{V}_{\mathrm{e}}$ diminishes, pressure $\mathrm{P}$ decreases, and the force becomes stronger to the right. The power piston now moves in the positive direction compressing the working fluid and the pressure increases. Forces proportional to $\left(\mathrm{P}_{\mathrm{m}}-\mathrm{P}\right)$ are thus seen to be quadrature forces leading the motion. Such forces are driving forces And the displacer and the piston are subject to such forces. In each case, the force proportional to $\left(\mathrm{P}_{\mathrm{m}}-\mathrm{P}\right)$ is the force that drives the motion, acting on either the displacer rod area or the piston area.

The electrical power output of the convertor depends on the force extracted by the alternator. The output power can be modeled as a function of temperature using equations (1) and (2). 


\section{Thermal Model}

The thermal cycle is modeled as an electric circuit. The circuit analogy uses current as the analog of heat flow in watts. It uses voltage as the analog of temperature in Kelvins. Conduction and convection losses are modeled when a temperature difference is connected across a thermal resistance. Heat storage is modeled as a capacitor. The electric circuit analogy is a convenient means to insure that heat balances are maintained. Since currents and voltages are constrained to follow circuit laws, so the analogous heat flows and temperatures will always balance. A current source is used to model the heater power applied to the convertor. The thermal model is shown in Figure 3.

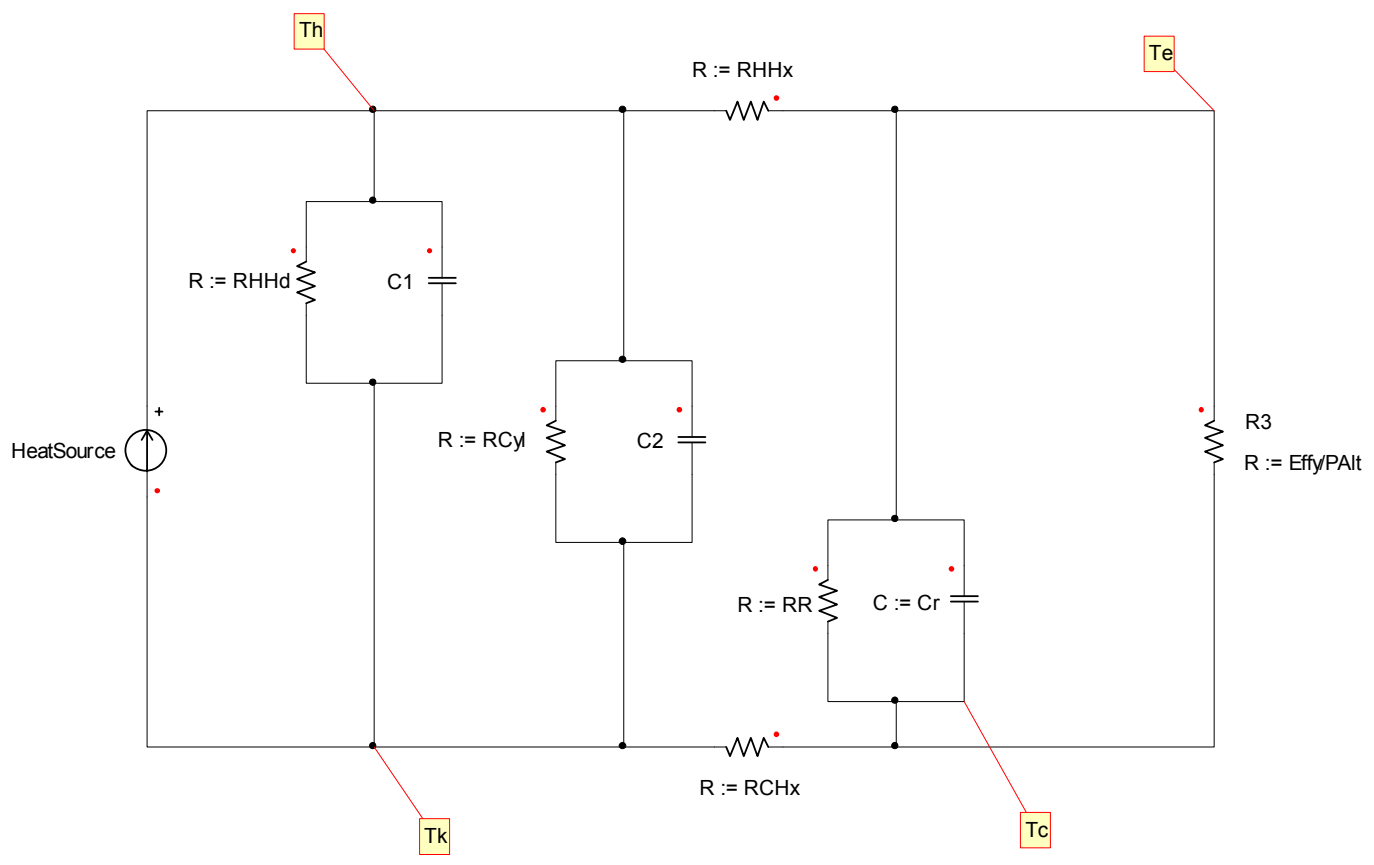

FIGURE 3. Thermal Circuit Analogy.

The heat output of the heat source is divided amongst the parallel circuit paths shown. RHHd is the conduction path from hot end to cold end offered by the metal of the heater head. $\mathrm{C} 1$ is a storage element that is proportional to the heat capacity of the heater head material and the volume of that material present in the heater head. In a similar way, $\mathrm{RCyl}$ and $\mathrm{C} 2$ model the displacer cylinder and $\mathrm{RR}$ and $\mathrm{Cr}$ model the regenerator. A regenerator temperature profile can be modeled if the single $\mathrm{RR}$ and $\mathrm{Cr}$ combination is replaced by several similar cells connected together in series. A simple way of modeling the heat used in the cycle is shown in the resistor on the right. Its value is numerically equal to the efficiency divided by the measured value of alternator power. So that the source heat drawn when the alternator is generating rated power can be set to the rated input power by adjusting the efficiency appropriately. It is possible to use the circuit diagram technique to model the thermodynamics of the cycle in more detail than shown in Figure 3. R3 would be replaced by a resistor whose value varies according to heat transfer coefficients of the heat exchangers and the simulated pressures, temperatures and fluid velocities. The circuit model computes temperatures $T_{e}, T_{c}$ and $T_{h}$. The cold end temperature, $T_{k}$, is usually specified by the user directly.

One of the challenges of controller design for the Free Piston Stirling convertor lies in the behavior of the thermal cycle. The expansion space temperature will rise if the alternator power decreases. The rise in temperature will tend to increase cycle power rather than decrease it. For a few cycles at least, there will be a tendency towards instability accompanying step changes in load. The effect needs to be countered by the control system if a well-regulated output is to be achieved. For this reason, a model that captures this thermal behavior is thought to be valuable in controller design. 


\section{Alternator and Controller Models}

Electromagnetic field simulation software has been used at GRC for a few years now to analyze linear alternators used in Stirling convertors (Geng, 2001). Use of techniques developed with such software enables the end-to-end dynamic model to consider electromagnetic field effects for which no closed form solutions exist (Nasar and Boldea, 1997). Examples are end turn inductance, slot loss and permanent magnet heating. The technique is to use the field simulation software to calculate coil flux as parameters of interest are varied. So the mover position, the stator current and perhaps the ambient temperature are varied and flux calculated for each condition. If 10 values are taken for each of the three parameters then 1000 field simulations would be needed. The 1000 simulations will yield 1000 total coil flux numbers. The resulting coil flux numbers are then compiled into a table and inserted into the dynamic model. Appropriate values of flux are drawn from the table and interpolated when the model is simulated. Since EMF is the time derivative of coil flux, model uses the table, with piston position, load current and time to calculate alternator EMF.

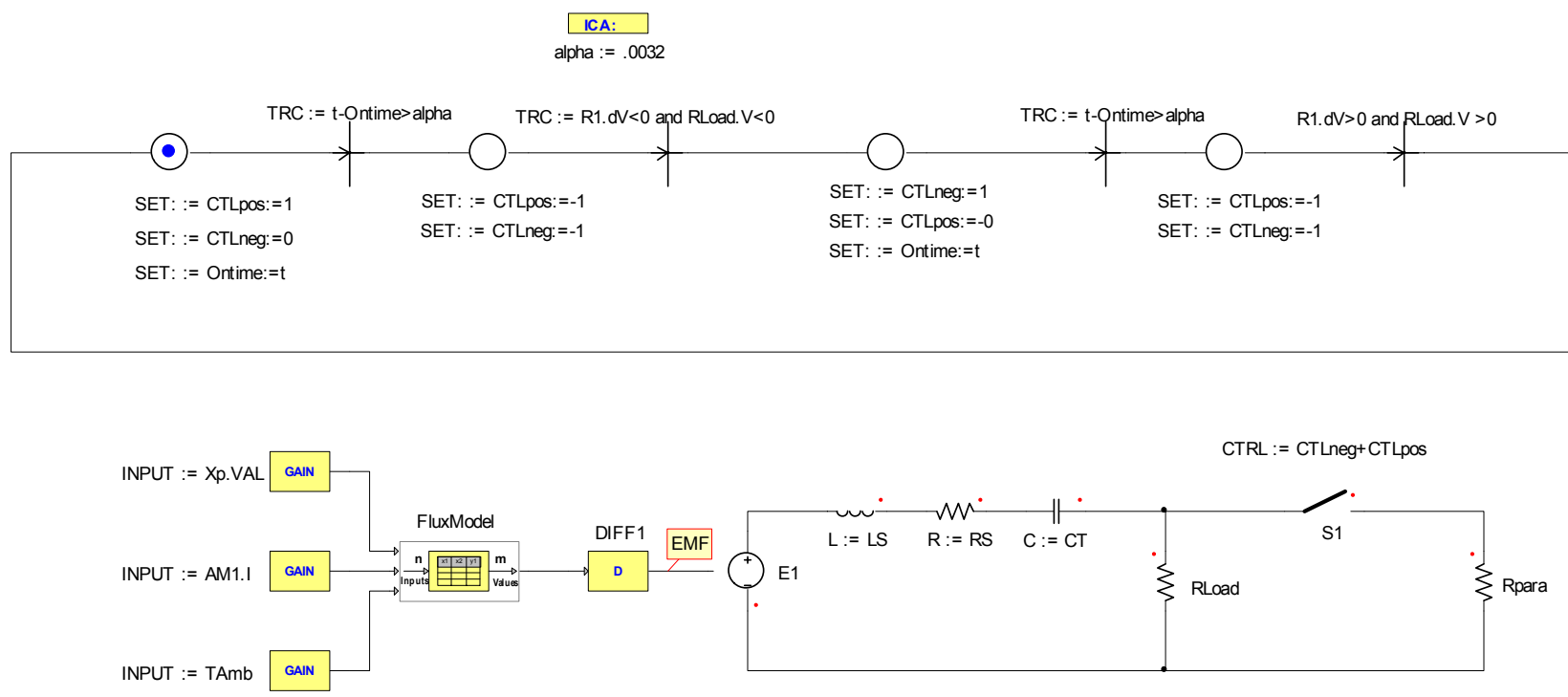

FIGURE 4. Controller and Alternator Models.

Again, applying the philosophy of the model, it is possible to determine the effect of a change to alternator core laminations by simulating the alternator configuration in the field simulation software and running the dynamic model with the resulting flux table as an EMF. The effect of such a change can be simulated and evaluated using the end-to-end model approach.

State diagram techniques are available in modern multi-simulation environments. State diagrams can speed the development of power electronics models. Using the state diagram, a simulation result such as a terminal voltage can be observed and state transitions can be made based on its instantaneous value. Switches or component values can be modified when a new state is entered. Consider, for example, the controller circuit shown in Figure 4. The state machine observes the terminal voltage. State transitions are made at zero crossings.

\section{Simulation Results/Verification of Model}

Each subsystem is developed on its own as a stand-alone system. Each has been individually tested with satisfactory results. GRC has hardware against which the model results is currently being compared. The 55W TDC built by Stirling Technology Company (STC) for DOE are installed and running in a test cell at GRC. With particulars of the STC convertor design entered into the end-to-end model, STC's controller circuit will be used to verify performance. Waveforms and temperatures predicted by the model will be compared to actual measurements for various input power levels. The results of such a comparison will indicate the level of accuracy of the model. GRC 
also has two of STC's 350W convertors available for test. It is hoped that the model can be verified against these as well. Agreement with both hardware units would be taken as a demonstration that the model scales correctly.

\section{Future Plans}

The end-to-end dynamic model is the first stage of an analytical system being developed at NASA Glenn. In order to be truly useful to NASA, its predictions will need to agree with those of industry standard design/analysis codes such as Sage. Modern software allows interaction between programs. It is hoped that heat transfer results and loss evaluations and all the other accomplishments of Sage can be acquired by this dynamic model as a means of making its predictions more accurate. In order to accomplish this kind of interaction, the system must have a reliable means of synchronizing the input data to both programs.

The model now takes physical arrangement input in the form of a few key coordinated dimensions and masses. An improvement will be made when the machine described by those dimensions can be presented in sketch form. Such a facility will be an aid to the analyst's intuition by showing a representation of what is being modeled. Another area which can be investigated is the evaluation of sensitivity of dynamic performance to dimension changes. Manufacturing tolerances relate directly to cost. Sensitivity analysis can be used as a tool with which to study the tolerance problem. Sensitivity analysis with respect to dimension change can also be used in reliability analysis. It is known that dimensions will not stay the same over many years of operation in space. The sensitivity dynamic operation to such changes may be of great interest.

\section{CONCLUSION}

A framework for an end-to-end dynamic model of the free piston Stirling convertor was presented in detail. The framework takes advantage of the availability of multi-simulation software environments that are now available. When such a model is used, the individual subsystems can be managed by specialists in the individual field: heat transfer, gas dynamics, power electronics or electric machines. The modeling software and means of interaction amongst the subsystems is straightforward enough to allow it. The subsystems are combined and overall convertor performance is simulated so that changes can be analyzed and development direction can be discerned.

\section{REFERENCES}

Benvenuto, G. and de Monte, F., "Electrodynamic Analysis of Free-Piston Stirling Engine/Linear Alternator Systems," in proceedings of the $29^{\text {th }}$ Intersociety Energy Conversion Engineering Conference (IECEC 1994), pp. 1866-1872, 1994.

Berchowitz, D., Urieli, I., and Rallis, C.J., "Computer Simulation of Stirling Cycle Machines," in proceedings of the $12^{\text {th }}$ Intersociety Energy Conversion Engineering Conference (IECEC 1977), pp. 1512-1521, 1977.

Geng, S., Schwarze, G., Niedra, J., and Regan, T., "A 3-D Magnetic Analysis of a Stirling Convertor Linear Alternator Under Load," in proceedings of $36^{\text {th }}$ Intersociety Energy Conversion Engineering Conference (IECEC 2001), pp. 441-446, 2001.

Nasar, S. and Boldea, I., Linear Electric Actuators and Generators, Cambridge University Press, 1997, Chapter 8, "Linear Electric Generators."

Redlich, R.W., Berchowitz, D.M., "Linear Dynamics of Free-Piston Stirling Engines," Proceedings of the Institution of Mechanical Engineers," Vol. 199, No. A3, pp. 203-213, 1985.

Ulusoy, N. and McCaughan, F., "Nonlinear analysis of Free Piston Stirling Engine/Alternator System," in proceedings of $29^{\text {th }}$ Intersociety Energy Conversion Engineering Conference (IECEC 1994) pp. 1847-1852. 


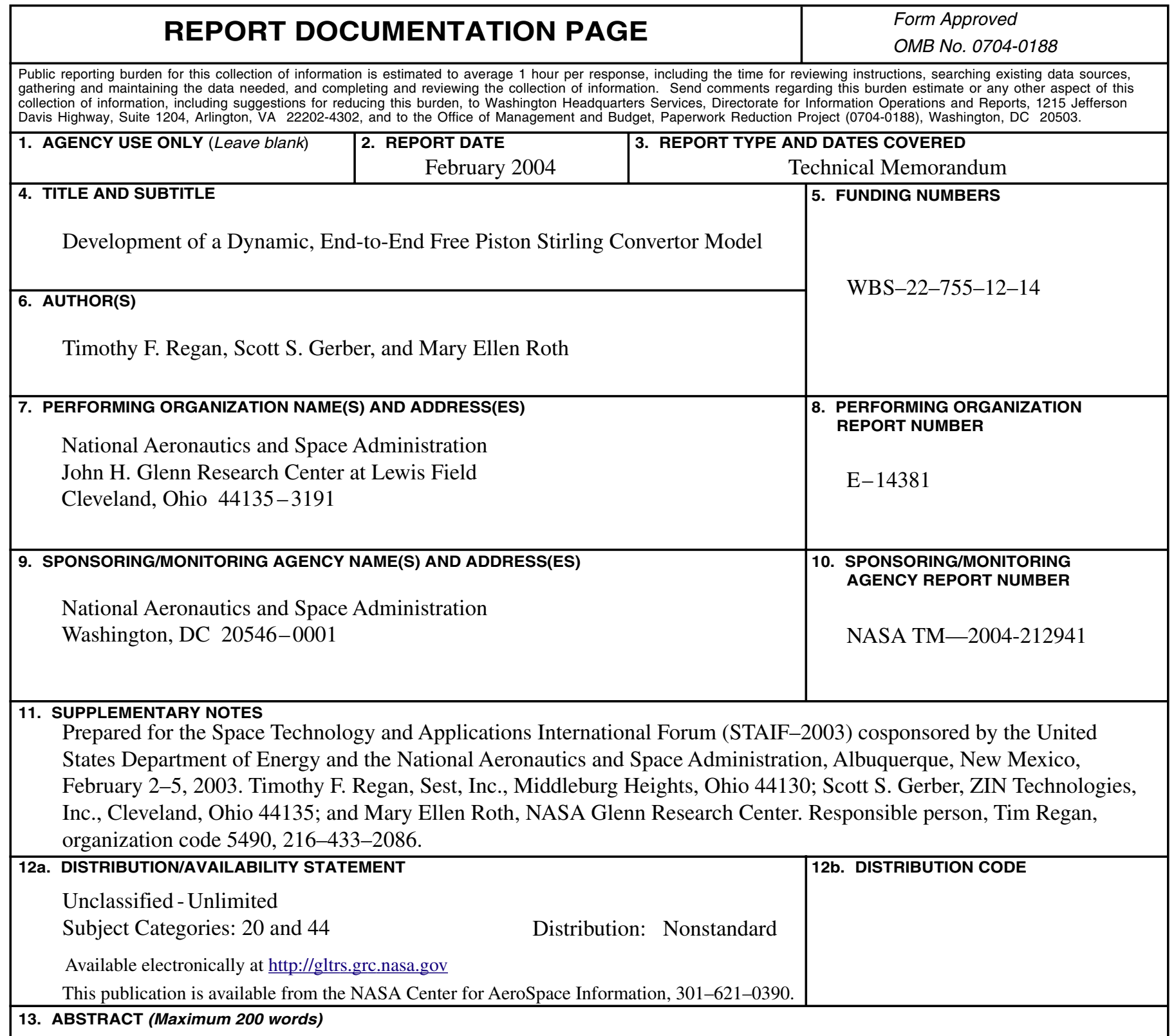

A dynamic model for a free-piston Stirling convertor is being developed at the NASA Glenn Research Center. The model is an end-to-end system model that includes the cycle thermodynamics, the dynamics, and electrical aspects of the system. The subsystems of interest are the heat source, the springs, the moving masses, the linear alternator, the controller, and the end-user load. The envisioned use of the model will be in evaluating how changes in a subsystem could affect the operation of the convertor. The model under development will speed the evaluation of improvements to a subsystem and aid in determining areas in which most significant improvements may be found. One of the first uses of the end-toend model will be in the development of controller architectures. Another related area is in evaluating changes to details in the linear alternator.

14. SUBJECT TERMS 15. NUMBER OF PAGES

Stirling engines; Design analysis; Block diagrams; Electromechanics; Dynamic models; Simulation; AC generators; Linear alternators; Stirling cycle

\begin{tabular}{|c|c|c|}
\hline $\begin{array}{c}\text { 17. SECURITY CLASSIFICATION } \\
\text { OF REPORT } \\
\text { Unclassified }\end{array}$ & $\begin{array}{c}\text { 18. SECURITY CLASSIFICATION } \\
\text { OF THIS PAGE } \\
\text { Unclassified }\end{array}$ & $\begin{array}{c}\text { 19. SECURITY CLASSIFICATION } \\
\text { OF ABSTRACT } \\
\text { Unclassified }\end{array}$ \\
\hline
\end{tabular}

